\title{
MANAJEMEN SPECIAL EVENT AJB BUMIPUTERA 1912 BANDUNG MELALUI CUSTOMER GATHERING
}

\author{
Chintia Melva Cahaya L. Tobing ${ }^{1}$, Susie Perbawasari ${ }^{2}$, dan Lukiati Komala Erdinaya ${ }^{3}$ \\ ${ }^{1}$ PT. Naos International \\ 2,3Universitas Padjadjaran
}

\begin{abstract}
ABSTRAK
Asuransi Jiwa Bersama (AJB) Bumiputera 1912 merupakan salah satu perusahaan asuransi di Indonesia yang sudah berdiri lebih dari seratus tahun. Di tengah goncangan ekonomi, AJB Bumiputera 1912 tetap berjalan stabil. Hal ini tidak lepas dari kepercayaan pelanggan yang tetap loyal menjadi mitra AJB Bumiputera, serta upaya dari perusahaan dalam membangun hubungan baik dengan pelanggan, karena bagi perusahaan pelanggan merupakan hal utama. Untuk mempertahankan hubungan baik tersebut, AJB Bumiputera 1912 Bandung memutuskan untuk mempertahankan loyalitas pelanggannya dengan mengadakan special event customer gathering di Kantor Wilayah Bandung. Tujuan penelitian ini adalah untuk mengetahui manajemen special event customer gathering AJB Bumiputera 1912 Bandung di Soreang dalam mempertahankan loyalitas pelanggan. Penelitian ini adalah penelitian deskriptif dengan jenis penyajian data kualitatif. Teknik pengumpulan data dilakukan dengan wawancara mendalam, observasi partisipan aktif, dan studi kepustakaan, dengan teknik pengumpulan key informant purposive sampling. Teknik analisis data menggunakan tiga tahap yaitu reduksi data, penyajian data, serta penarikan kesimpulan. Teknik validitas data menggunakan triangulasi sumber. Hasil penelitian menunjukkan bahwa manajemen special event AJB Bumiputera 1912 Bandung melalui customer gathering di Soreang dilakukan dengan riset informal melalui focus group discussion (FGD). Hasil riset menyatakan bahwa calon peserta yang akan diundang adalah para pejabat sesuai kriteria produk menjadi indikator loyalitas dan konsep acara semiformal. Desain acara dilakukan dengan pemilihan tema elegan, mewah, dan semiformal.
\end{abstract}

Kata-kata Kunci: Special event, loyalitas pelanggan, ghatering, pelanggan, focus group discussion

\section{SPECIAL EVENT MANAGEMENT OF AJB BUMIPUTERA 1912 BANDUNG THROUGH CUSTOMER GATHERING}

\begin{abstract}
Asuransi Jiwa Bersama (AJB) Bumiputera 1912 is one of the insurance companies in Indonesia that has stood for more than one hundred years. In the midst of economic shocks, AJB Bumiputera 1912 remains stable. This can not be separated from the trust of customers who remain loyal to AJB Bumiputera partners, as well as the efforts of the company in building good relations with customers, because for the customer company is the main thing. To maintain such good relations, AJB Bumiputera 1912 Bandung decided to maintain customer loyalty by holding a special event customer gathering in Bandung Regional Office. The study aims to determine the Event management process by AJB Bumiputera 1912 Bandung in Customer gathering in Soreang to maintain customer loyalty. This study is a descriptive studies used a qualitative approach. Data was collected by in-depth interviews, active participant observation, and literature study. The key informant collection technique used is purposive sampling. Data were analyzed using three stages, which is data reduction, data display, and conclusion drawing. Validity of the data using triangulation of sources. The results of this study showed that Event management process of AJB Bumiputera 1912 Bandung throughout of customer gathering in Soreang doing the research through informal research and focus group discussion (FGD). Results of research suggests that the candidates who will be invited are the officials that able to but the products that sell in the Event to be an indicator of loyalty and the Event concept is semiformal.
\end{abstract}

Keywords: Special event, customer loyalty, ghatering, customer, focus group discussion

Korespondensi: Chintia Melva Cahaya L. Tobing, S. I. Kom. Human Resources Consultant PT Naos International. Tl.49 Jakarta Selatan.Email: chintyamct@gmail.com 


\section{PENDAHULUAN}

Asuransi Jiwa Bersama (AJB) Bumiputera 1912 merupakan salah satu perusahaan asuransi di Indonesia yang tertua, yang sudah berdiri sejak tahun 1912, atau telah berusia lebih dari 100 tahun. Di tengah begitu banyaknya goncangan ekonomi, AJB Bumiputera 1912 tetap dapat mengembangkan sayapnya dan tetap berjaya sebagai industri yang tetap berjalan stabil. Bagi perusahaan semacam AJB Bumiputera 1912, pelanggan merupakan hal utama.

Namun, seiring berjalannya waktu, AJB Bumiputera 1912 menyadari bahwa persaingan dalam dunia asuransi tentu sangat tinggi. Perubahan besar yang terjadi pada 2015 adalah dibukanya pasar bebas ASEAN atau yang biasa disebut Masyarakat Ekonomi ASEAN (MEA). MEA adalah peluang sekaligus tantangan bagi industri asuransi di Indonesia yang sampai dengan September 2015 terdapat lebih dari 137 perusahaan asuransi konvensional, yang terdiri dari perusahaan asuransi jiwa, perusahaan asuransi umum, perusahaan reasuransi, perusahaan yang menyediakan asuransi wajib dan asuransi sosial.

Dengan kesadaran tersebut, AJB Bumiputera 1912 Bandung pun memutuskan memilih sebuah strategi untuk mempertahankan loyalitas pelanggannya yakni dengan mengadakan special event customer gathering di Kantor Wilayah Bandung. Melalui manajemen hubungan pelanggan yang baik, AJB Bumiputera 1912 Bandung berharap dapat mencapai tujuannya yakni mempertahankan loyalitas pelanggannya.

Customer gathering yang diadakan oleh kantor wilayah Bandung ini diselenggarakan oleh tiap kantor cabang dengan melibatkan kantor wilayah sebagai sebagai perancang konsep. Peneliti memilih meneliti acara customer gathering yang diadakan di kantor cabang Soreang karena target peserta yang diundang pada cabang ini hampir seluruhnya merupakan petinggi perusahaan dan jumlahnya lebih banyak dari cabang-cabang lain karena setaraf kabupaten.

Special event customer gathering AJB Bumiputera 1912 cabang Soreang yang diadakan pada tanggal 26 Agustus 2015 ini, dilaksanakan di Restoran Sutan Raja Hotel Soreang. Acara ini diisi dengan acara hiburan dan makan bersama, presentasi mengenai company profile, perkembangan perusahaan dan mengenai produk terbarunya. Mitra BPMaxi, serta penjualan produk yang disertai dengan promosi-promosi pembelian asuransi yang berhadiah. Terdapat proses manajemen special event yang dilakukan oleh AJB Bumiputera 1912 kantor wilayah Bandung dan kantor cabang Soreang sebagai penyelenggara customer gathering di Soreang, yakni riset, desain, perencanaan, koordinasi dan evaluasi.

\section{METODE PENELITIAN}

Penelitian ini memaparkan mengenai tahapan manajemen special event customer gathering oleh AJB Bumiputera 1912 Bandung di Soreang dalam mempertahankan loyalitas pelanggan. Penelitian dilakukan menggunakan metode deskriptif dengan paradigm positivistik dan penyajian data kualitatif.

Paradigma menurut Harmon (dalam Moleong, 2007: 49) merupakan cara mendasar untuk mempersepsi, berfikir, menilai, dan melakukan yang terkait dengan sesuatu secara khusus tentang visi realitas. Nasution menyatakan bahwa paradigma ialah suat perangkat kepercayaan nilai-nilai tentang dunia sekitar. Paradigma mengarahkan penelitian dengan timbulnya paradigma baru tentang dunia, timbul pula paradigma baru dalam peneitian serta metode yang digunakan. Paradigma baru memberikan dorongan kuat dan segar untuk mengadakan penemuan baru (Nasution, 1992: 2).

Penelitian ini menggunakan paradigma positivistik yang memandang sebuah realitas sebagai sesuatu yang bisa dipahami dan diasumsikan hadir, yang dikendalikan oleh hukum-hukum alam dan mekanisme yang tidak dapat diubah. Dalam penelitian ini, paradigma positivistik digunakan sebagai cara mendasar untuk mempersepsi proses manajemen special event customer gathering AJB Bumiputera 1912 secara objektif untuk mengetahui bagaimana proses kegiatan manajemen special 
event yang dilakukan dan bagaimana cara kerja yang seharusnya terjadi sesuai acuan dalam melakukan analisis.

Penelitian ini menggunakan metode deskriptif dengan jenis penyajian data kualitatif. Menurut Isaac dan Michael (dalam Rakhmat 2009: 22), metode deskriptif bertujuan melukiskan secara sistematis fakta atau karakteristik populasi tertentu secara faktual dan cermat. Penelitian ini tidak mencari atau menjelaskan hubungan, tidak menguji hipotesis atau membuat prediksi, namun hanya memaparkan secara sitematis manajemen special event customer gathering yang dilakukan oleh AJB Bumiputera 1912.

Jenis data kualitatif dibutuhkan dalam penelitian ini karena penelitian ini meneliti sebuah proses kerja, terdapat data-data yang tidak dapat dikuantifikasikan dalam bentuk analisis statistik. Dalam penerapannya, peneliti mendeskripsikan proses manajemen special event dengan mengeksplorasi dan memberikan gambaran lengkap yang berkaitan dengan tahapan riset, desain, perencanaan, koordinasi serta evaluasi dalam kegiatan customer gathering yang dilakukan oleh AJB Bumiputera 1912

Adapun cara menentukan informan adalah dengan teknik purposive sampling, yaitu teknik penentuan sampel dengan pertimbangan tertentu (Sugiyono, 2012: 122). Adapun pertimbangan peneliti dalam merumuskan kriteria key informant adalah sebagai berikut: Mereka yang sudah mendalami visi, misi, dan budaya perusahaan AJB Bumiputera 1912 Bandung, Mereka yang berkecimpung atau terlibat pada kegiatan customer gathering AJB Bumiputera 1912 Bandung di Soreang tahun 2015 selama dua kali diadakan, Mereka yang sudah bekerja di AJB Bumiputera 1912 Bandung dan di Soreang selama lebih dari 5 tahun, dan Mereka yang bersedia menyampaikan informasi hasil sesuai data dan fakta yang tersedia dalam database AJB Bumiputera 1912 Bandung.

Teknik pengumpulan data yang digunakan untuk dalam penelitian ini adalah observasi, wawancara mendalam, dan studi pustaka. Untuk teknik analisis data, peneliti menggunakan teknik analisis data menurut Miles dan
Huberman (dalam Sugiyono, 2010: 246), yakni, analisis data kualitatif terdiri atas tiga alur kegiatan yang terjadi secara bersamaan yaitu: reduksi data, penyajian data, dan penarikan kesimpulan dan verifikasi.

Adapun teknik validasi data yang dipergunakan dalam penelitian ini menggunakan teknik Triangulasi. Denzin (dalam Moleong, 2007: 330) membedakan empat macam triangulasi sebagai teknik pemeriksaan yang memanfaatkan pengguanaan sumber, metode, penyidik, dan teori. Peneliti menggunakan triangulasi sumber data sebagai metode untuk menggabungkan data. Peneliti membandingkan hasil wawancara dari sumber penelitian dengan kenyataan di lapangan. Peneliti membandingkan hasil wawancara dengan pihak AJB Bumiputera 1912 Bandung dengan triangulator, yakni kepala wilayah AJB Bumiputera 1912 wilayah Bandung, Rolexon Napitupulu, untuk melihat bagaimana proses manajemen special event customer gathering AJB Bumiputera 1912 Bandung di Soreang.

\section{HASIL DAN PEMBAHASAN}

Event biasanya digunakan sebagai sebuah strategi merealisasikan tujuan sebuah perusahaan. Dalam proses manajemen special event, tahapan pertamayang dilaksanakan adalah riset. Riset berguna untuk menganalisis situasi atau masalah yang ada. Riset juga dibutuhkan untuk menentukan kebutuhan, keinginan dan ekspektasi para peserta. Riset menurut Cutlip, Center, Broom (2005: 334) digunakan untuk mengidentifikasi tujuan utamanya sebagai upaya mengurangi ketidakpastian dalam pembuatan keputusan. Sementara Pudjiastuti (2010: 1) mengatakan bahwa riset awal untuk menganalisis situasi sangat perlu dilakukan agar dapat diperoleh data dan fakta yang aktual sebagai bahan pembuatan perencanaan Special event. Pengumpulan data dapat dilakukan melalui survei, wawancara, FGD (focus group discussion), kliping, analisis media, atau melalui data sekunder.

AJBBumiputera 1912 Soreang, berdasarkan konsep special event melaksanakan riset dengan menggunakan FGD (focus group discussion) 
antara kepala AJB Bumiputera 1912 cabang Soreang yang diarahkan oleh kantor wilayah Bandung dengan para agen dan supervisor dengan pertimbangan sudah sangat mengenal dan memahami peserta yang akan diundang dan juga memiliki bekal yang banyak dari evaluasi acara serupa yang sudah pernah dilaksanakan oleh cabang-cabang AJB Bumiputera 1912 wilayah Bandung.

Dalam proses mempelajari hasil evaluasi customer gathering, Kepala Divisi Pemasaran bersama dengan Public Relations Officer (PRO) AJB Bumiputera 1912 wilayah Bandung mengumpulkan hasil evaluasi dari berbagai kegiatan bersama para nasabah dan pelanggan. Hasil dari mempelajari evaluasi tersebut ditemukanlah hal-hal yang harus dihindari. Pertama, sebaiknya mengadakan customer gathering, selain di tempat yang sudah dikenal dan gampang dijangkau, tempatnya juga harus menyediakan lahan parkir yang luas. Kedua, mengenai pemilihan waktu, AJB Bumiputera 1912 Bandung dan cabang Soreang memutuskan untuk mengadakan customer gathering di siang hari.

Proses riset selanjutnya yang AJB Bumiputera 1912 Bandung dan cabang Soreang lakukan adalah melaksanakan rapat dengan para agen. Dalam rapat bersama para agen, hal yang ingin ditemukan dalam rapat bersama para agen ini adalah bagaimana kriteria nasabah yang akan diundang menjadi peserta dan bagaimana pengemasan acara yang sesuai dengan kebutuhan para calon peserta dan tujuan customer gathering itu sendiri. Setelah dilakukan rapat bersama para agen, ditentukanlah bahwa dalam customer gathering kali ini, kriteria nasabah yang akan dijadikan calon peserta adalah nasabah yang dianggap memiliki pemahaman tentang investasi, sesuai dengan kriteria produk BP Maxi dan memiliki kemampuan untuk membelinya.

Dalam tahapan manajemen special event, AJB Bumiputera 1912 Bandung dan Soreang telah melaksanakan riset dengan bentuk informal yakni dengan menggunakan informan kunci. Informan kunci ini terdiri dari pihak-pihak yang sudah pernah terlibat dan memahami kondisi perusahaan di antara banyak pesaing dan di mata para nasabah, yakni petinggi kantor wilayah Bandung yang sudah berpengalaman menangani berbagai acara yang melibatkan nasabah dan para agen yang sudah mengenal para nasabah. Terdapat dua metode riset menurut Cutlip, Center, Broom (2005: 334) yaitu riset informal dan formal. Riset formal ialah riset yang dilakukan secara formal menggunakan instrumen seperti survei, dan informal menggunakan instrumen informan kunci dan sumber online.

Meskipun riset yang dilakukan AJB Bumiputera 1912 adalah riset informal namun perusahaan telah melakukan hal yang dianggap penting dalam suatu program. Ruslan (2007) menyatakan bahwa penelitian (research) merupakan hal yang sangat vital dalam membuat suatu perencanaan program PR.

Tujuan dari diadakannya Customer gathering ini adalah untuk mempertahankan loyalitas pelanggan. Menurut Griffin (Griffin, 2003: 5) dalam bukunya "Customer Loyalty" seorang pelanggan dapat dikatakan loyal bila menunjukkan perilaku pembelian yang didefinisikan sebagai pembelian nonrandom yang diungkapkan dari waktu ke waktu oleh beberapa unit pengambilan keputusan.

Proses desain menurut Goldblatt (2014: 54) dimulai dengan brainstorming. Brainstorming dilakukan antara AJB Bumiputera 1912 wilayah Bandung dan cabang Soreang untuk menemukan ide-ide unik dalam menciptakan desain acara. Menurut Berndt H. Schmitt (dalam Pudjiastuti, 2010: 28), special event diharapkan dapat memberikan pengalaman pada pengunjung melalui 1) sense, 2) think, 3) act, 4) relate, dan 5) feel. Special event sebaiknya menyentuh perasaan pengunjung melalui penglihatan, sentuhan, rasa, pendengaran, dan penciumannya. Pengunjung harus mampu merasakan emosi yang membekas, seperti keceriaan dan kenyamanan untuk menimbulkan rasa empati.

Dalam special event customer gathering di Soreang tema yang ditetapkan adalah elegan, mewah, dan semi formal. Pemilihan tema diharapkan mampu menciptakan pengalaman yangdapatmenambahwawasan dan pengetahuan pengunjung, serta mengubah sikapnya. Special 
event selalu berusaha memberikan pengalaman spesial bagi pengunjungnya. Untuk memenuhi hal tersebut, desain dalam sebuah special event harus dirancang secara matang dengan mempertimbangkan berbagai unsur untuk menarik perhatian pengunjung. Unsur-unsur special event yang harus diperhatikan menurut Pudjiastuti (2010: 31) meliputi: 1) unsur gerak, 2) unsur suara, 3) unsur warna, dan 4) unsur cahaya. Unsur-unsur ini dapat diterapkan pada dekorasi, lighting, penyusunan kursi dan meja, ruangan, panggung, musik dan hiburan, susunan acara, protokoler, MC, dan sebagainya (Pudjiastuti, 2010: 30).

Unsur gerak dan suara dalam customer gathering AJB Bumiputera 1912 di Soreang, ditunjukkan dengan hiburan dan pengisi acara. Hiburan dan pengisi acara disesuaikan dengan tema yang diusung, elegan, mewah, dan semi formal. Hiburan ditunjukkan dengan adanya penampilan musik, yaitu band lokal, agar mendukung tema, yaitu tidak kaku. Untuk pengisi acara, yang dipilih adalah seorang announcer radio terkenal di Bandung, yang dianggap sudah kredibel menjadi MC acara semiformal. Untuk pengisi acara lainnya, para petinggi, kepala bidang pemasaran,

Desain pencahayaan dan warna ditunjukkan dengan dekorasi, lighting, dan penuansaan yang sesuai dengan tema. Dalam customer gathering AJB Bumiputera 1912 di Soreang, dekorasi, lighting dan penuansaan mengikuti desain tempat awalnya, yakni Restoran Sutan Raja Hotel. Untuk lighting, karena cuaca ketika dilaksanakannya customer gathering adalah siang hari, dan tempatnya memiliki banyak kaca jendela yang mempermudah masuknya sinar matahari, tidak terlalu banyak variasi di dalamnya. Namun, kondisi panggung dan layar slide tepat membelakangi posisi matahari yang mengakibatkan pencahayaan tepat berada pada posisi panggung membuat slide presentasi dan yang berada di depan menjadi sulit untuk diperhatikan.

Proses perencanaan special event harus disusun dengan sangat teliti dan matang, mengingat fungsinya yang penting sebagai pedoman pelaksanaan acara. Perencanaan disusun berdasarkan data-data yang didapat dari hasil riset yang telah dilakukan sebelumnya. Rumusan perencanaan yang matang akan menghasilkan suatu program PR yang efektif (Ruslan, 2007). Dalam perencanaan, langkahlangkah yang dilaksanakan olehAJBBumiputera 1912 Bandung dan Soreang yakni, merancang timeline yang tersusun dari hari pertama rapat antarpegawai kantor cabang dan para agen, lalu di waktu yang sama para agen menghubungi para peserta via telepon. Hari kedua panitia melakukan reservasi Restoran dan pemilihan menu, serta menghubungi pengisi acara, dari mulai MC dan biduan serta pemain musik dan mereview kembali materi yang biasanya sudah disediakan dari pusat.

Lalu pada hari ketiganya undangan yang ditujukan ke para peserta yang sudah mengkonfirmasi bersedia hadir yang diantarkan oleh para agen kepada para pesertanya. Lalu hari keempat adalah pelaksanaan. Dalam proses perencanaan special event costumer gathering AJB Bumipuera 1912 melibatkan karyawan dan manajemen guna terbinanya hubungan jangka panjang dengan pelanggan. Membangun hubungan jangka panjang yang kokoh dengan pelanggan memerlukan usaha yang penuh konsentrasi dari semua karyawan dan pihak manajemen untuk mengetahui apa yang memuaskan pelanggan dan apa yang dihargai oleh pelanggan, karena apa yang dihargai oleh pelanggan lebih luas dari apa yang tampaknya disadari oleh banyak manajer (Barnes, 2003: 7).

Perencanaan special event berlangsung setelah melakukan riset dan menetapkan tujuan yang ingin dicapai tahapan selanjutnya adalah melakukan proses desain yang merupakan sebuah proses kreatif dan pengembangan konsep. Selanjutnya tim penyelenggara melakukan perencanaan untuk mewujudkan acara yang sesuai dengan konsep agar acara berjalan lancar dan tercapainya tujuan awal dari acara.

AJB Bumiputera 1912 cabang Soreang, memperhatikan timing dengan tujuan untuk mengumpulkan informasi yang mencakup jenis dan bentuk kegiatan, pihak atau publik yang terlibat, tindakan dan strategi yang akan diambil. Taktik yang dimiliki AJB Bumiputera 1912 cabang Soreang sangat singkat. Penyelenggara 
menganggap telah mempelajari banyak dari pelaksanaan sebelumnya dan hasil evaluasinya. Perencanaan dilakukan dalam 3 hari yang sudah termasuk rapat perencanaan, reservasi segala hal untuk acara dan menyebarkan undangan.

Space mengacu pada ruang fisik lokasi acara. Berdasarkan kebutuhan acara, AJB Bumiputera 1912 cabang Soreang memilih Restoran Sutan Raja Hotel karena cukup ternama di Soreang yang cukup kredibel untuk acara-acara yang berkelas sesuai dengan kriteria peserta yang adalah petinggi-petinggi. Desain dan suasana tempatnya mendukung acara customer gathering. Pertimbangan lokasi yang mudah dijangkau karena berada di Soreang, yang masih dekat dengan Bandung, kondisi tata letak ruangannya yang mendukung kondisi gathering atau kebersamaan, dan luas wilayahnya. Kegiatan yang dilakukan ini sebetulnya merupakan bagian dari manajemen kerelasian pelanggan atau lebih dikenal dengan Customer Relationship Management (CRM) merupakan salah satu strategi untuk menciptakan kepercayaan pelanggan (Anisa, 2016).

Tempo ialah ritme kerja yang berlangsung selama perencanaan hingga produksi. Customer gathering AJB Bumiputera 1912 di Soreang dilaksanakan pada Rabu, 26 Agustus 2015 dengan persiapan waktu dari 4 hari sebelum pelaksanaan. Tempo meliputi jadwal persiapan, proses produksi, dan peralatan. Pada tahap ini, langkah yang dilakukan adalah mereservasi tempat, menghubungi MC dan grup band.

Untuk menjaga kekompakan dalam sebuah tim diperlukan koordinasi yang baik. Dengan koordinasi akan tercipta sebuah pola kerja yang efektif dalam melakukan sebuah kerja profesional. Dalam pelaksanaan Customer gathering AJB Bumiputera 1912 Bandung di Soreanginihanyaterdapatpanitiapelaksanayang tergolong kecil. Semua orang yang memegang peran adalah orang-orang yang bekerja di dalam AJB Bumiputera 1912 Bandung dan Soreang. Pertama, kepala bagian marketing dan Public Relations Officer (PRO) AJB Bumiputera 1912 wilayah Bandung, M. Fatoroni dan Heru Triantoro, terlibat dalam mempersiapkan konsep acara yang diinstruksikan untuk dilaksanakan di tiap cabang sesuai instruksi dari kantor AJB Bumiputera 1912 pusat. Lalu, Jajang Johari kepala AJB Bumiputera 1912 cabang Soreang, bertindak sebagai ketua pelaksana. Yanti, Staff AJB Bumiputera 1912 Soreang, selaku bagian acara, dan Irfan, Staff AJB Bumiputera 1912 Soreang, selaku bagian logistik, serta para agen dan supervisor yang bertindak sebagai perwakilan perusahaan yang berhubungan langsung dengan para peserta.

Special event melibatkan banyak pihak. Apabila tidak ada koordinasi yang baik, setiap komponen dalam special event akan berjalan sendiri-sendiri sehingga tidak dapat menajdi satu kesatuan yang utuh untuk mencapai tujuannya. Penyusunan panitia pelaksanaan dalam customer gathering AJB Bumiputera 1912 di Soreang memiliki dynamic structure dalam kepengurusannya, dynamic structure menurut Goldblatt (2014: 136) yaitu: "Begins with a small team and then escalates to a large group and then returns to its small size following the delivery of the event"

Pihak-pihak dalam special event antara lain bagian catering, peneliti, bagian hiburan, bagian publikasi, bagian grafik, bagian dekorasi, bagian musik dan sebagainya, dalam hal ini manajer acara harus mampu mengoordinasi semua pihak secara baik dan adil sehingga mereka merasa puas terhadap perlakuan dan kerja yang telah dilakukan (Pudjiastuti, 2010: 95). Pada customer gathering AJB Bumiputera 1912 Bandung di Soreang, penyelenggara melakukan koordinasi kebanyakan lewat rapat. Manajer acara adalah kepala AJB Bumiputera 1912 cabang Soreang. Koordinasi yang perlu dilakukan yakni kepada bagian hiburan, $\mathrm{MC}$ dan grup band, pengurus acara, Yanti, yang akan berkoordinasi dengan pihak catering, bagian dekorasi dan logistik, Irfan, para agen dan supervisor yang merupakan penghubung dengan peserta, dan pihak kantor wilayah yang merupakan pengonsep acara dan pembawa presentasi juga. Pada proses koordinasi sebaiknya dipastikan pesan telah selaras tersebar oleh semua anggota panitia (Ramadhan, Hafiar, \& Komariah, 2016).

Bekerja dalam tim memerlukan kiat tersendiri agar setiap anggotanya mampu bekerja sama dengan baik. Ada beberapa 
tantangan yang seringkali harus dihadapi tim. Menurut Goldblatt (dalam Pudjiastuti 2010:97), tatangan tersebut adalah faktor komunikasi kepentingan pribadi, komitmen, kepercayaan, dan kolaborasi, dan ditambahkan tanggung jawab dan disiplin tim, serta dukungan pimpinan.

Seluruh kegiatan yang telah selesai dilaksanakan, wajib untuk dievaluasi. Hasil evaluasi ini penting untuk menjadi acuan bagi perencanaan event selanjutnya, atau kegiatan serupa. Proses evaluasi dalam customer gathering AJB Bumiputera 1912 Bandung di Soreang dilakukan dua kali yakni dengan mengadakan rapat kepala cabang dengan para agen dan supervisor, dan mengadakan rapat kepala wilayah dan semua cabang.

Proses evaluasi di kantor cabang tidak berfokus pada teknis pelaksanaan event. Evaluasi hanya dilakukan terhadap para agen tentang bagaimana feedback para peserta yang mereka ajak pada pembelian produk yang dijadikan indikator keloyalan para peserta. Dalam evaluasi bersama para panitia, pembahasan mengenai teknis acara juga tidak terlalu dipermasalahkan. Kekurangan-kekurangan spesifik dalam acara tidak dibahas, yang dibahas lebih kepada peroses perencanaan, mengenai penentuan peserta dan pemilihan hari.

Hasil evaluasi acara menunjukkan belum tercapainya tujuan secara maksimal dikarenakan ada kesalahan yang sebagian besar dalam penetapan waktu. Tingkat loyalitas yang dinilai dari penjualan yang berlangsung menunjukkan bahwa produk yang dipasarkan yang terjual sebesar 4 unit.

Goldblatt (2014: 64) menjelaskan bahwa tahap evaluasi dilakukan setelah melakukan proses riset, desain, perencanaan, dan koordinasi acara. Evaluasi kemudian dilakukan dan tahap selanjutnya ialah kembali lagi pada tahap riset. Hal ini menunjukkan bahwa evaluasi telah yang dilakukan dapat dijadikan data riset untuk kegiatan serupa berikutnya.

Menurut Bill Penn (dalam Pudjiastuti 2010, 70), untuk mengevaluasi sukses tidaknya suatu special event, beberapa faktor yang perlu diperhatikan, yaitu: penjualan, liputan media, dan pendapat atau perilaku khalayak. Untuk liputan media sebaiknya juga direncanakan teknik evaluasi dengan menghitung jumlah liputan yang didapat dan menentukan sifat pemberitaan, apakah positif atau negatif (Hartono, Dida, \& Hafiar, 2015).

Dalam mengadakan acara Customer gathering di AJB Bumiputera 1912 Bandung

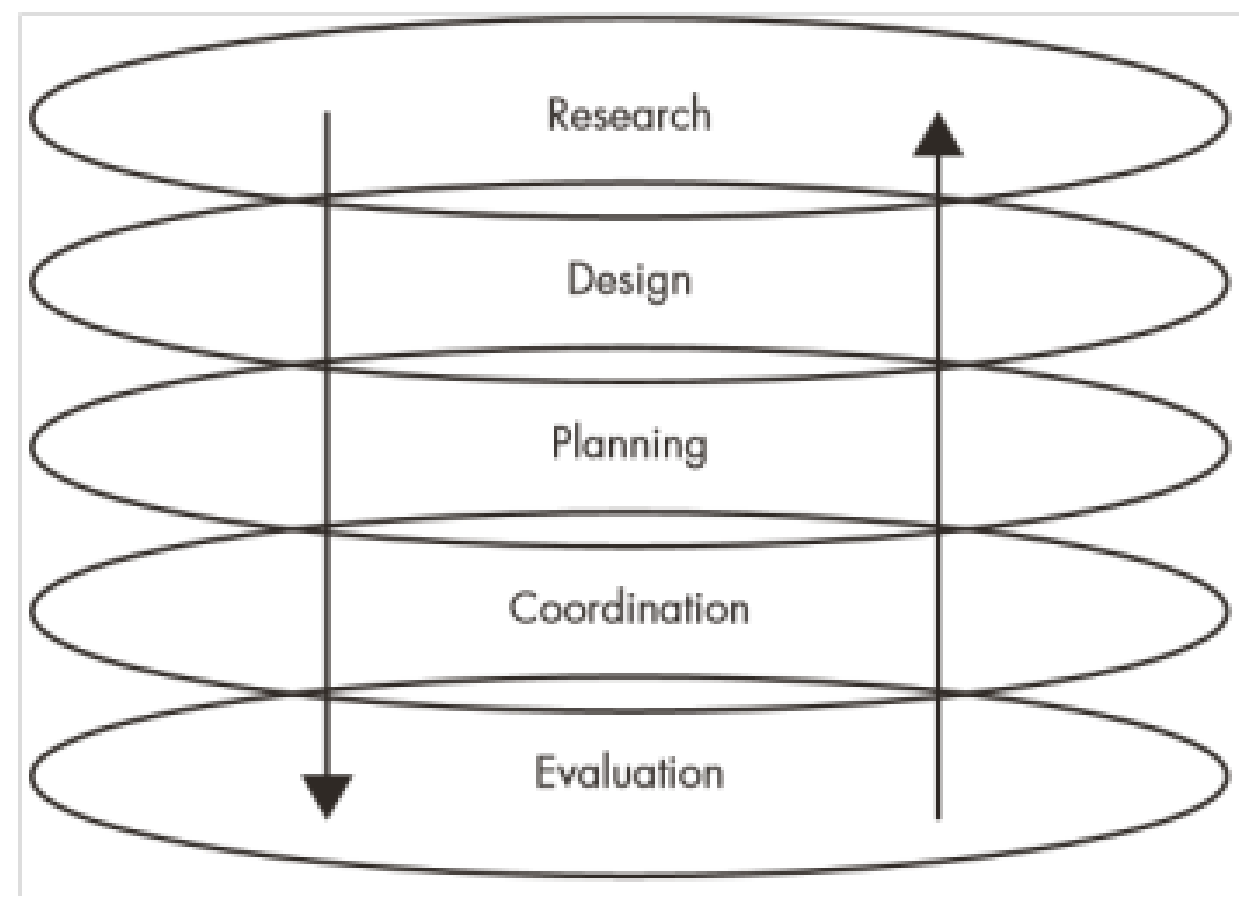

Sumber: Goldblatt (2014: 64)

\section{Gambar 1 Planned Event process}


di Soreang, jika ditilik dari langkah evaluasi di atas, maka: 1). Penjualan yang berlangsung menunjukkan bahwa produk yang dipasarkan yang terjual sebesar 4 unit. Dengan target pembelian yang seharusnya adalah $50 \%$ dari jumlah peserta yang hadir. Pada customer gathering di AJB Bumiputera 1912 Bandung di Soreang tanggal 26 Agustus 2015 yang lalu, jumlah peserta yang hadir adalah 42 orang dan yang melakukan pembelian adalah 4 orang yang tidak menyentuh angka $10 \%, 2$ ). AJB Bumiputera 1912 Bandung dalam mengadakan customer gathering tidak mengundang media dan menginginkan adanya publisitas dan 3). Setelah mengikuti customer gathering tujuan kedua setelah mempertahankan loyalitas adalah menanamkan nilai keakraban.

Setelah acara berakhir hubungan para agen dan nasabah tetap terjalin dan beberapa peserta memutuskan untuk mau bergabung, dengan demikian hubungan dengan publik terjalin dengan baik, baik dengan agen, nasabah, maupun calon nasabah. Wasesa (2006: 146) mengatakan: Secara umum, kepentingan pengusaha terhadap publik adalah bagaimana memanfaatkan keberadaan publik untuk mendapatkan keuntungan sebesar-besarnya bagi usaha yang dijalankan.

Pengukuran evaluasi kegiatan customer gathering juga memliki kriteria sendiri yang ditetapkan oleh AJB Bumiputera 1912 wilayah Bandung. Hal-hal tersebut, yakni: 1). Jumlah peserta yang hadir. Customer gathering yang baik, berhasil menghadirkan minimal 80\% dari jumlah undangan. 2). Pembelian produk yang dipasarkan dalam customer gathering oleh nasabah yang sudah pernah menggunakan produk AJB Bumiputera 1912 sebesar 50\% dari jumlah peserta.

Tujuan utama dari customer gathering di AJB Bumiputera 1912 Bandung di Soreang pada tanggal 26 Agustus 2015 adalah untuk mempertahankan loyalitas pelanggan. Definisi pelanggan yang loyal menurut Stum dan Thiry (Griffin, 2003: 31) adalah: Melakukan pembelian berulang secara teratur, membeli antarlini produk dan jasa, mereferensikan kepada orang lain, dan menunjukkan kekebalan terhadap tarikan pesaing.
Dalam customer gathering di AJB Bumiputera 1912 Bandung di Soreang, peserta yang membeli produk Mitra BP Maxi berarti termasuk dalam kategori loyal karena melakukan pembelian berulang secara teratur, yakni sekalipun masih menjadi pemegang polis untuk jenis asuransi lain di AJB Bumiputera 1912, mereka masih melakukan pembelian. Peserta juga membeli antarlini produk dan jasa, yang ditunjukkan dengan adanya kedekatan antara nasabah dan para agen. Mereferensikan kepada orang lain, ditunjukkan dengan adanya peserta yang datang dengan membawa orang lain, seperti keluarga atau rekannya. Dan dalam menunjukkan kekebalan terhadap tarikan pesaing. Hal itu dapat ditunjukkan dengan pembeli yang memutuskan bergabung membeli BP Maxi padahal jenis produk lebih mirip pada deposito atau investasi yang banyak dijual juga oleh industri asuransi atau bank lainnya.

\section{SIMPULAN}

AJB Bumiputera 1912 Bandung dan Soreang dalam pelaksanaan customer gathering sudah melakukan riset terlebih dahulu. Riset dilakukan dengan bentuk informal yakni dengan menggunakan informan kunci yang terdiri dari pihak-pihak yang sudah pernah terlibat dalam pelaksanaan customer gathering. Dari riset ditemukan bahwa peserta yang diundang adalah para pejabat di Soreang yang memahami investasi dan memiliki kemampuan membeli produk BP Maxi. Namun, sebaiknya tidak hanya melaksanakan riset secara informal, yakni hanya cara FGD (focus group discussion), tetapi juga riset formal dengan, tetapi juga dapat melalui survei, wawancara, kliping, analisis media, atau melalui data sekunder. Riset juga sebaiknya tidak hanya bersandar pada definisi dan interpretasi manajemen perusahaan sendiri.

Desain dalam customer gathering AJB Bumiputera 1912 di Soreang mengikuti tema yaitu elegan, mewah, dan semi formal. Unsur gerak dan suara ditunjukkan dengan hiburan dan pengisi acara. Unsur pencahayaan dan warna ditunjukkan dengan dekorasi, lighting dan penuansaan, yang mengikuti desain awal Restoran Sutan Raja Hotel. Namun, 
terabaikan dan berdampak pada posisi layar slide dan panggung yang membelakangi cahaya sehingga sulit untuk diperhatikan oleh peserta. Sebaiknya AJB Bumiputera 1912 Bandung dan cabang Soreang memperhatikan segala unsur-unsur desain dengan detail, jangan sampai mengabaikan satu unsur pun seperti pencahayaan dan unsur suara. Unsur pencahayaan juga harus dikondisikan dengan kondisi ruangan, layout, dan posisi panggung atau layar slide.

Perencanaan customer gathering AJB Bumiputera 1912 di Soreang disusun dalam bentuk timeline yang dilaksanakan tiga hari berturut-turut sebelum pelaksanaan. Penyusunan timeline sangat terburu-buru dan hanya berdasarkan evaluasi dan pengalaman yang terdahulu. Namun, timeline pengerjaan sebaiknya dibuat jauh-jauh hari, untuk mematangkan pelaksanaan. Jangan merasa cukup hanya dengan hasil evaluasi dan pengalaman saja. Semakin lama timeline yang direncanakan, semakin mudah untuk mengantisipasi adanya kekurangan-kekurangan dalam perencanaan.

Proses koordinasi customer gathering AJB Bumiputera 1912 di Soreang dilakukan saat rapat di awal perencanaan saja. Koordinasi dimulai dari kantor pusat yang memerintahkan kantor wilayah mengadakan customer gathering, lalu dari kantor wilayah Bandung menyusun konsep dan mengkoordinasikan kepada kantor cabang apa yang harus dilakukan. Namun, sebaiknya AJB Bumiputera 1912 Bandung dan cabang Soreang tetap mengadakan rapat bersama atau briefing antara kantor wilayah Bandung dan cabangnya untuk menyamakan persepsi minimal sebelum acara dimulai.

Dalam tahap evaluasi, proses evaluasi dilakukan dua kali yakni dengan mengadakan rapat kepala cabang dengan para agen dan supervisor, dan mengadakan rapat kepala wilayah dan semua cabang. Hasil evaluasi acara menunjukkan belum tercapainya tujuan secara maksimal. Namun, sebaiknya AJB Bumiputera 1912 Bandung dan cabang Soreang melakukan evaluasi yang membahas tahapan-tahapan dalam manajemen special event secara mendetail dan menyertakan tanggapan atau feedback dari para peserta, agar hasil yang diperoleh dapat menjadi pembelajaran dalam mengadakan special event tidak hanya dalam hal penjualan.

\section{DAFTAR PUSTAKA}

Anisa, R. (2016). Manajemen kerelasian pelanggan dalam menciptakan kepercayaan pelanggan pada. Jurnal Kajian Komunikasi, 4/1, 44-51

Barnes, J. G. (2003). Secrets of Customer Relationship Management. Yogyakarta: Andi

Cutlip, S. M. , \& Glen, M. B. (2005). Effective public relations. New Jersey: Prentince Hall

Data Otoritas Jasa Keuangan. (2015). OJK sebut industri perasuransian berperan penting dalam pembangunan nasional. Diakses dari http://www.ojk.go.id/ojk-sebutindustri-perasuransian-berperan-pentingdalam-proses-pembangunan-nasional pada 12 Desember 2015

Goldblatt, J. (2014). Special events: creating and sustaining a new world for celebration. New Jersey: John Wiley \& Sons, Inc

Griffin, J. (2003). Customer loyalty: menumbuhkan dan mempertahankan pelanggan. Jakarta: Airlangga

Hartono, N. A., Dida, S., \& Hafiar, H. (2015). Pelaksanaan kegiatan special event jakarta goes pink oleh lovepink indonesia. Jurnal Komunikasi, 10/2, 161-172

Moleong, (2007). Metodologi penelitian kualitatif. edisi Revisi. Bandung: Remaja Rosdakarya.

Nasution. (1992). Metode research. Bandung: Jemmars

Pudjiastuti, W. (2010). Special event: alternatif jitu membidik pasar. Jakarta: Elex Media Komputindo

Rakhmat, J. (2009). Metode penelitian komuinkasi. Bandung: Remaja Rosdakarya

Ramadhan, R. F., Hafiar, H., \& Komariah, K. (2016). Manajemen special event culture for peace oleh cioff indonesia. Jurnal Riset Komunikasi

Ruslan, R. (2007). Manajemen public relations dan media komunikasi. Jakarta: Raja Grafindo Persada

Sugiyono. (2010). Metode penelitian kuantitatif, kualitatif, dan $r \& d$. Bandung: Alfabeta 
(2012). Metode penelitian bisnis. $\quad$ Wasesa, S. A. (2006). Strategi public relations.

Bandung: Alfabeta

Jakarta: Gramedia Pustaka Utama 